\title{
Diagnostic and prognostic biomarker potential of kallikrein family genes in different cancer types
}

\author{
Prashant D. Tailor ${ }^{1,2}$, Sai Karthik Kodeboyina ${ }^{2}$, Shan Bai ${ }^{2}$, Nikhil Patel ${ }^{4}$, Shruti \\ Sharma ${ }^{2}$, Akshay Ratnani ${ }^{1,2}$, John A. Copland ${ }^{5}$, Jin-Xiong She ${ }^{2}$ and Ashok Sharma ${ }^{2,3}$ \\ ${ }^{1}$ Medical College of Georgia, Augusta University, Augusta, GA, USA \\ ${ }^{2}$ Center for Biotechnology and Genomic Medicine, Augusta University, Augusta, GA, USA \\ ${ }^{3}$ Department of Population Health Sciences, Augusta University, Augusta, GA, USA \\ ${ }^{4}$ Department of Pathology, Augusta University, Augusta, GA, USA \\ ${ }^{5}$ Mayo Clinic, Jacksonville, FL, USA \\ Correspondence to: Ashok Sharma, email: assharma@augusta.edu \\ Keywords: cancer; TCGA; kallikreins; gene expression; prognosis \\ Received: September 21, $2017 \quad$ Accepted: March 06, $2018 \quad$ Published: April 03, 2018 \\ Copyright: Tailor et al. This is an open-access article distributed under the terms of the Creative Commons Attribution License 3.0 \\ (CC BY 3.0), which permits unrestricted use, distribution, and reproduction in any medium, provided the original author and source \\ are credited.
}

\section{ABSTRACT}

Purpose: The aim of this study was to compare and contrast the expression of all members of the Kallikrein (KLK) family of genes across 15 cancer types and to evaluate their utility as diagnostic and prognostic biomarkers.

Results: Severe alterations were found in the expression of different Kallikrein genes across various cancers. Interestingly, renal clear cell and papillary carcinomas have similar kallikrein expression profiles, whereas, chromophobe renal cell carcinoma has a unique expression profile. Several KLK genes have excellent biomarker potential (AUC > 0.90) for chromophobe renal cell carcinoma (KLK2, KLK3, KLK4, KLK7, KLK15), renal papillary carcinoma ( $K L K 1, K L K 6, K L K 7)$, clear cell renal cell carcinoma (KLK1, $K L K 6)$, thyroid carcinoma $(K L K 2, K L K 4, K L K 13, K L K 15)$ and colon adenocarcinoma (KLK6, KLK7, KLK8, KLK10). Several KLK genes were significantly associated with mortality in clear cell renal cell carcinoma $(K L K 2: H R=1.69 ; K L K 4: H R=1.63 ; K L K 8$ : HR = 1.71; KLK10: HR = 2.12; KLK11: HR = 1.76; KLK14: HR = 1.86), papillary renal cell carcinoma $(K L K 6: H R=3.38, K L K 7: H R=2.50)$, urothelial bladder carcinoma $(K L K 5:$ HR $=1.89, K L K 6: H R=1.71, K L K 8: H R=1.60)$, and hepatocellular carcinoma $(K L K 13:$ HR = 1.75).

Methods: The RNA-seq gene expression data were downloaded from The Cancer Genome Atlas (TCGA). Statistical analyses, including differential expression analysis, receiver operating characteristic curves and survival analysis (Cox proportionalhazards regression models) were performed.

Conclusions: A comprehensive analysis revealed the changes in the expression of different KLK genes associated with specific cancers and highlighted their potential as a diagnostic and prognostic tool.

\section{INTRODUCTION}

The human kallikrein (KLK) gene family is the largest contiguous cluster of serine proteases within the human genome [1]. The 15 members of the kallikrein gene family are located on chromosome 19q13.4 [2]. KLK3, or prostate-specific antigen (PSA), is the most recognized member of the family with its ubiquitous use in prostate cancer screening [1]. Kallikreins are known to play a role in several physiological processes including, extracellular 
matrix (ECM) remodeling, cellular proliferation, angiogenesis, differentiation, apoptosis, digestive system enzyme activation and coagulation-fibrinolysis [3-5]. Members of the kallikrein family are often expressed in a tissue-specific manner and are regulated by transcriptional and post-transcriptional mechanisms such as steroid hormones (androgen response elements) and serpins, respectively [5-8]. Like other proteases, kallikreins are first secreted as zymogens in both intra and extracellular environments and are activated via other serine proteases or auto-activation $[6,9]$. Kallikreins are inactivated by internal cleavage, alpha2-macroglobulin and serpins to prevent excessive proteolytic activity $[5,6]$. There is huge variability in the expression of each kallikrein in different tissue types throughout the body $[5,6,10]$.

Kallikreins have also been implicated in regulation of tumor growth, neoplastic progression, tumor angiogenesis and metastasis $[1,5,9,11-25]$. For example, KLK1, KLK2 and $K L K 3$ can increase degradation of the ECM with their proteolytic effects on fibronectin, laminin, gelatin, fibrinogen and collagenases leading to metastasis $[5,11-16]$. In addition, KLK1-3 have been shown to degrade IGFbinding proteins, releasing free IGF, which increases tumor cell proliferation and survival $[5,14-16]$. KLK4 has been shown to increase the activation of plasmin via activation of urokinase plasminogen activator (uPA) which helps with angiogenesis, invasion, and metastasis of the tumor $[5,17]$. KLK6 and 7 have been implicated in cancer angiogenesis and metastasis by its proteolytic effects cleaving fibrinogen, collagen and laminin [5, 18]. KLK13 has been shown to have anti-angiogenic properties by creating angiostatin-like fragments, which inhibit angiogenesis [5, 19]. Finally, the kallikreins can activate one another, and cross-activation of kallikreins may be related to malignancies $[5,6,20,21]$.

Kallikreins have shown promise as diagnostic biomarkers, including $K L K 3$, which is widely used for screening of prostate cancer $[6,12]$ and have been associated with prognosis and mortality [21-23]. For example, $K L K 15$ expression is an independent marker of prognosis in ovarian cancer [2], KLK9 has been shown to be a marker for prognosis in breast and ovarian cancer $[1,5,6,21]$, and increased $K L K 11$ expression in gastric carcinoma is associated with poor prognosis [24].

Since different kallikreins have huge variations in expression and function across different tissues, a comprehensive analysis was performed to examine the expression of all members of the kallikrein family genes in different cancer types using The Cancer Genome Atlas (TCGA) gene expression data. The main objectives of this study were to (i) compare and contrast expression of Kallikrein genes across 15 different cancers, (ii) elucidate the effect of kallikreins on the cancer prognosis, and (iii) to evaluate the utility of Kallikrein family as cancer biomarkers.

\section{RESULTS}

\section{KLK expression changes across cancers}

All fifteen members of the kallikrein family (KLK115) had their expression analyzed in fifteen different cancer types using the gene expression data from TCGA. We have included a table that details the number of tumor and control samples for each cancer type (Table 1). The fold change values comparing tumor and adjacent normal samples are displayed in Figure 1. Bonferroni corrected $p$-value $(p<0.0033)$ was used for statistical significance. All KLKs with at least 2-fold up or down with $p<0.0033$ are highlighted in Figure 1. Mean expression values in tumor and adjacent normal, fold-changes and $P$-values for each KLK and cancer are included in Supplementary Materials (Supplementary Table 1). The dot-plots showing the distribution of gene expression in cancer patients and adjacent normal for each KLK are shown in Supplementary Materials (Supplementary Figure 1).

In three types of renal cancers (renal papillary carcinoma, renal clear cell carcinoma and chromophobe renal cell carcinoma), we observed major alterations in the KLK gene expressions. Renal clear cell carcinoma and renal papillary carcinoma solely experienced downregulation of KLK gene expressions; whereas, chromophobe renal cell carcinoma had a combination of increased and decreased expression across the kallikrein family. The renal papillary carcinoma and renal clear cell carcinoma had dramatically decreased expression of $K L K 1$ (52-fold and 94-fold), KLK6 (45-fold and 42-fold) and KLK7 (33-fold and 48-fold), respectively. Chromophobe renal cell carcinoma had increased expression of the following KLKs: KLK1 (32-fold), KLK2 (12-fold), KLK3 (69-fold), KLK4 (234-fold), KLK15 (132-fold), whereas decreased expression of KLK5 (5-fold), KLK6 (13-fold), and $K L K 7$ (26-fold). A Venn diagram summarizing our main findings in these three types of renal cancers is shown in Figure 2.

With regards to colon adenocarcinoma and thyroid carcinoma, the following KLKs were significantly elevated: KLK6 (106-fold and 12-fold), KLK7 (19-fold and 24-fold), KLK10 (15-fold and 31-fold), KLK11 (4fold and 20-fold), KLK12 (3-fold and 5-fold), while the following KLKs were significantly downregulated: $K L K 1$ (4-fold and 7-fold), KLK3 (4-fold and 3-fold), KLK15 (6fold and 6-fold). In addition, thyroid carcinoma displayed significant downregulation of KLK2 (13-fold) and KLK4 (9-fold).

Lung adenocarcinoma and lung squamous cell carcinoma showed significant up-regulation of 3 KLKs: KLK6 (7-fold and 19-fold), KLK8 (3-fold and 15-fold) and KLK12 (2-fold and 3-fold) and significant downregulation of KLK11 (6-fold and 5-fold). Five KLKs were commonly downregulated in head-neck squamous cell carcinoma and breast invasive carcinoma: KLK3 
Table 1: Number of tumor and control samples from 15 cancers analyzed in this study

\begin{tabular}{lccc}
\hline Cancer type & TCGA code & Tumor samples & Control samples \\
\hline Breast invasive carcinoma & BRCA & 1097 & 114 \\
Kidney renal clear cell carcinoma & KIRC & 533 & 72 \\
Head and neck squamous cell carcinoma & HNSC & 520 & 44 \\
Lung adenocarcinoma & LUAD & 515 & 59 \\
Thyroid carcinoma & THCA & 505 & 59 \\
Lung squamous cell carcinoma & LUSC & 502 & 51 \\
Prostate adenocarcinoma & PRAD & 497 & 52 \\
Stomach adenocarcinoma & STAD & 415 & 35 \\
Bladder urothelial carcinoma & BLCA & 407 & 19 \\
Liver hepatocellular carcinoma & LIHC & 371 & 50 \\
Kidney renal papillary cell carcinoma & KIRP & 290 & 32 \\
Colon adenocarcinoma & COAD & 286 & 41 \\
Esophageal carcinoma & ESCA & 184 & 11 \\
Uterine corpus endometrial carcinoma & UCEC & 176 & 24 \\
Kidney chromophobe & KICH & 66 & 25 \\
\hline
\end{tabular}

(3-fold and 4-fold), KLK6 (2-fold and 6-fold), KLK7 (2fold and 10-fold), KLK11 (5-fold and 6-fold) and KLK13 (8-fold and 3-fold). Prostate adenocarcinoma and urothelial bladder carcinoma exhibited significant upregulation of $K L K 2$ and $K L K 4$ gene expressions (KLK2: 3-fold and 2-fold, KLK4: 3-fold and 2-fold). Furthermore, uterine corpus endometrial carcinoma displayed significant overexpression of $K L K 12$ (3-fold) and downregulation of $K L K 1$ (5-fold), KLK2 (4-fold) and KLK4 (6-fold). In each of the following cancers, only one KLK was significantly upregulated: hepatocellular carcinoma (KLK4: 2-fold), stomach adenocarcinoma (KLK6: 11-fold) and esophageal carcinoma (KLK4: 3-fold). The summary of these changes in the expression of KLKs in different cancers is presented in Figure 1.

\section{Viability of KLKs as cancer biomarkers}

To evaluate the biomarker potential of KLKs in 15 cancers, we computed the area under the curve (AUC) of receiver operating characteristic (ROC) curves. The AUC values of all KLKs in 15 cancers are listed in Supplementary Materials (Supplementary Table 1). KLK genes with excellent biomarker potential in different cancers ( $>5$ fold up or down and AUC $>0.90$ ) are shown in Table 2. The ROC curves of up-regulated KLKs with AUC $>0.90$ and boxplots depicting their distribution in control and tumor samples are shown in Figure 3. Colon cancer had four up-regulated KLKs with excellent AUC values (KLK6: 0.988, KLK7: 0.939, KLK8: 0.928, KLK10: $0.905)$. Chromophobe renal cell carcinoma also had 4 upregulated KLKs with excellent diagnostic power (KLK2: 0.990, KLK3: 0.974, KLK4: 0.989, KLK15: 0.97). KLK13 has an AUC value of 0.902 for thyroid carcinoma.
We also found few downregulated KLKs with AUC $>0.90$ as shown in Figure 4. Renal papillary cancer had three KLKs with an AUC of at least 0.90 (KLK1: 0.943, KLK6: 0.902, KLK7: 0.906). Renal clear cell carcinoma had two KLKs with classification power above the AUC threshold (KLK1: 0.921, KLK6: 0.928). Thyroid carcinoma had three KLKs (KLK2: 0.943, KLK4: 0.914, KLK15: 0.905) that had AUC values above 0.90 threshold and KLK7 had an AUC of 0.910 in Chromophobe renal cell carcinoma. These findings are summarized in Table 2.

\section{KLKs and prognosis relationship across cancers}

Each of the 15 members of the kallikrein family was independently assessed across the 15 cancers to determine if the expression of kallikrein is associated with overall survival. Prognosis of four (renal clear cell carcinoma, renal papillary carcinoma, urothelial bladder carcinoma, and hepatocellular carcinoma) out of 15 cancers, was found to be significantly associated with kallikrein genes (Figure 5). Renal clear cell carcinoma had six KLKs in which increased expression was associated with overall survival $(K L K 2: \mathrm{HR}=1.69 ; K L K 4: \mathrm{HR}=1.63 ; K L K 8$ : $\mathrm{HR}=1.71 ; K L K 10: \mathrm{HR}=2.12 ; K L K 11: \mathrm{HR}=1.76$; and $K L K 14: \mathrm{HR}=1.86)$. In renal papillary carcinoma, increased expression of $K L K 6(\mathrm{HR}=3.38)$ and $K L K 7$ $(\mathrm{HR}=2.50)$ was associated with a significant worsened prognosis. In urothelial bladder carcinoma, increased expression of KLK5, 6 and 8 was associated with increased mortality with hazard ratios of $1.89,1.71$, and 1.60 , respectively. In hepatocellular carcinoma, increased expression of KLK13 was significantly associated with increase in mortality $(\mathrm{HR}=1.75)$. 


\begin{tabular}{|c|c|c|c|c|c|c|c|c|c|c|c|c|c|c|c|}
\hline & 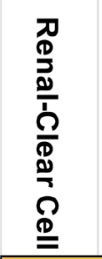 & 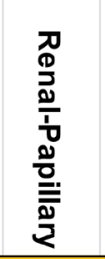 & 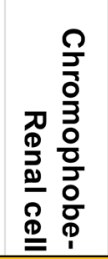 & $\begin{array}{l}\Omega \\
0 \\
0 \\
0 \\
1 \\
\frac{1}{2} \\
\frac{2}{0} \\
\frac{1}{0} \\
0\end{array}$ & $\begin{array}{l}\frac{1}{2} \\
\frac{1}{0} \\
\text { 을 }\end{array}$ & $\begin{array}{l}\text { E } \\
5 \\
0 \\
0 \\
\frac{1}{1} \\
0 \\
\frac{0}{10} \\
\frac{1}{0}\end{array}$ & 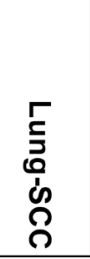 & 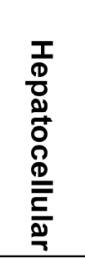 & 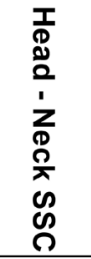 & 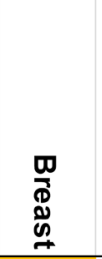 & 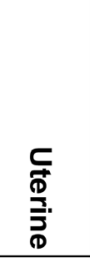 & 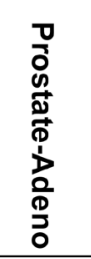 & $\begin{array}{l}\frac{\boldsymbol{m}}{\mathbf{0}} \\
\frac{0}{2} \\
\frac{0}{\mathbf{0}}\end{array}$ & 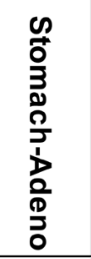 & 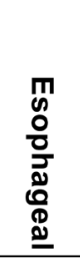 \\
\hline KLK5 & -6.45 & -7.22 & -5.24 & 1.39 & 2.66 & -3.70 & -1.07 & 1.02 & 1.16 & -11.12 & 1.09 & -1.48 & 2.43 & -1.37 & 2.57 \\
\hline KLK7 & -33.33 & -48.03 & -25.65 & 18.93 & 24.06 & -4.76 & -1.07 & 1.09 & -2.43 & -10.00 & 1.07 & -1.43 & 2.05 & 2.00 & 6.08 \\
\hline KLK11 & -1.87 & -1.46 & -1.82 & 3.46 & 19.54 & -5.56 & -4.78 & -5.06 & -5.06 & -6.05 & -1.29 & -1.39 & -2.12 & -2.52 & -2.17 \\
\hline KLK10 & -2.22 & -1.30 & -2.01 & 14.99 & 31.33 & -5.56 & -1.67 & -5.24 & -1.74 & -5.37 & 1.25 & -1.71 & -1.52 & 2.44 & 5.86 \\
\hline KLK6 & -45.15 & -41.55 & -13.05 & 105.92 & 12.22 & 6.91 & 18.70 & 1.23 & -2.42 & -6.45 & -1.37 & -1.78 & 3.34 & 11.47 & 17.04 \\
\hline KLK8 & -1.31 & -1.29 & -1.50 & 14.29 & 1.91 & 2.96 & 15.15 & 1.06 & -1.52 & -7.22 & 1.04 & -1.07 & 1.89 & 2.87 & 11.65 \\
\hline KLK1 & -51.78 & -94.19 & 31.98 & -4.31 & -7.25 & -1.32 & 1.36 & 1.26 & -2.44 & -1.77 & -4.80 & -1.89 & -1.17 & 1.85 & 1.90 \\
\hline KLK3 & -2.15 & -4.62 & 68.93 & -4.34 & -3.45 & -1.59 & -1.30 & 1.57 & -3.09 & -4.07 & -2.21 & 2.92 & 1.44 & 1.49 & 1.56 \\
\hline KLK15 & -2.41 & -2.77 & 131.90 & -6.42 & -6.14 & 1.15 & 1.26 & 1.26 & -1.24 & 1.05 & 1.06 & 4.96 & 1.15 & 1.40 & 1.09 \\
\hline KLK2 & 1.22 & -1.39 & 12.37 & 1.17 & -13.22 & -1.01 & 2.09 & 1.93 & -1.40 & -2.12 & -3.72 & 3.45 & 2.02 & 1.48 & 1.96 \\
\hline KLK4 & 1.04 & 1.30 & 233.88 & -1.86 & -9.24 & 1.17 & 1.98 & 2.04 & 1.38 & 4.92 & -6.08 & 2.76 & 2.22 & 1.92 & 3.22 \\
\hline KLK13 & 1.45 & 1.41 & 1.66 & -3.53 & 6.28 & -1.15 & 2.29 & 1.39 & -8.17 & -2.74 & 1.64 & -1.30 & -1.50 & -2.01 & -1.57 \\
\hline KLK12 & 1.03 & -1.05 & 1.06 & 2.99 & 5.33 & 2.36 & 3.37 & -1.10 & -8.33 & 1.07 & 3.06 & 2.78 & -1.30 & -4.00 & -1.25 \\
\hline KLK14 & 1.46 & 1.58 & 1.59 & -1.25 & -1.09 & -1.30 & 1.48 & 1.14 & 1.61 & -2.16 & 1.57 & 2.05 & 1.00 & 1.15 & 1.45 \\
\hline KLK9 & 1.07 & 1.02 & 1.02 & 1.74 & 1.08 & 1.35 & 6.77 & -1.03 & 1.83 & -1.02 & 1.48 & 1.00 & 1.69 & -1.17 & 4.89 \\
\hline
\end{tabular}

Figure 1: Kallikrein expression fold change in specific cancers. Each member of the kallikrein (KLK) family is listed vertically and the 15 cancers are displayed horizontally. Values highlighted in blue or orange represent a fold change greater than 2 or less than 0.5 ( -2 fold) respectively while having a $p$-value of less than 0.0033 . The vertical and horizontal order was determined by unsupervised clustering of both kallikreins and cancers.

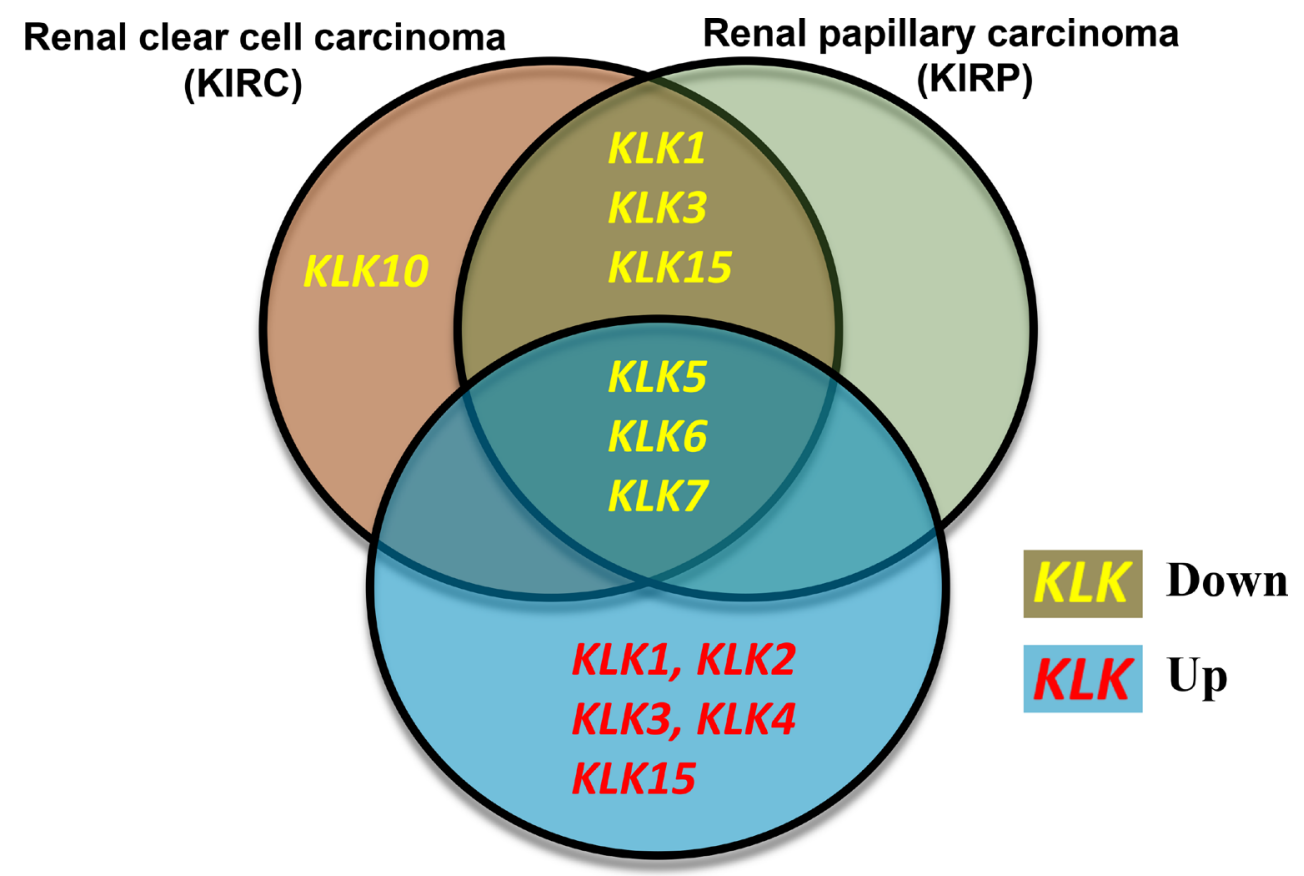

Chromophobe renal cell carcinoma

(KICH)

Figure 2: Venn diagram comparing the expression changes of kallikreins in three types of renal cancers. Renal clear cell carcinoma and renal papillary carcinoma show similarities in the kallikrein expression changes whereas Chromophobe renal cell carcinoma shows a distinct kallikrein expression profile. Yellow font reflects downregulation whereas red font indicates upregulation of kallikrein expression in carcinoma. 
Table 2: KLK genes with excellent biomarker potential in 15 different cancer types

\begin{tabular}{|c|c|c|c|c|c|c|}
\hline Cancer & Gene & Fold change & $P$-value & $\begin{array}{c}\text { Normal mean } \\
\pm \text { SD }\end{array}$ & $\begin{array}{c}\text { Tumor mean } \pm \\
\text { SD }\end{array}$ & $\operatorname{AUC}(95 \% \mathrm{CI})$ \\
\hline \multicolumn{7}{|c|}{ Up-regulated genes } \\
\hline COAD & KLK6 & 105.9 & 4.14E-100 & $1.40 \pm 1.57$ & $148.76 \pm 7.28$ & $0.988(0.983-0.993)$ \\
\hline COAD & KLK7 & 18.9 & $2.29 \mathrm{E}-70$ & $1.21 \pm 1.30$ & $22.81 \pm 7.69$ & $0.939(0.926-0.952)$ \\
\hline COAD & KLK8 & 14.3 & $1.94 \mathrm{E}-64$ & $1.08 \pm 1.23$ & $15.48 \pm 7.41$ & $0.928(0.914-0.942)$ \\
\hline COAD & KLK10 & 15.0 & $3.52 \mathrm{E}-45$ & $25.53 \pm 1.80$ & $382.65 \pm 6.09$ & $0.905(0.888-0.922)$ \\
\hline $\mathrm{KICH}$ & KLK2 & 12.4 & $6.54 \mathrm{E}-24$ & $1.11 \pm 1.21$ & $13.73 \pm 3.75$ & $0.990(0.981-0.999)$ \\
\hline $\mathrm{KICH}$ & KLK3 & 68.9 & $9.91 \mathrm{E}-29$ & $3.49 \pm 2.23$ & $240.58 \pm 3.28$ & $0.974(0.960-0.988)$ \\
\hline $\mathrm{KICH}$ & KLK4 & 233.9 & $5.51 \mathrm{E}-38$ & $4.37 \pm 2.03$ & $1021.30 \pm 4.94$ & $0.989(0.980-0.998)$ \\
\hline $\mathrm{KICH}$ & KLK15 & 131.9 & $1.81 \mathrm{E}-33$ & $4.05 \pm 2.16$ & $534.27 \pm 4.51$ & $0.970(0.955-0.985)$ \\
\hline THCA & KLK13 & 6.3 & $1.19 \mathrm{E}-31$ & $3.57 \pm 2.03$ & $22.41 \pm 3.01$ & $0.902(0.888-0.916)$ \\
\hline \multicolumn{7}{|c|}{ Down-regulated genes } \\
\hline $\mathrm{KICH}$ & KLK7 & -25.7 & $2.96 \mathrm{E}-07$ & $34.89 \pm 10.15$ & $1.36 \pm 1.56$ & $0.910(0.871-0.949)$ \\
\hline KIRC & KLK1 & -51.8 & 4.34E-24 & $157.70 \pm 9.57$ & $3.05 \pm 6.51$ & $0.921(0.900-0.942)$ \\
\hline KIRC & KLK6 & -45.2 & $6.02 \mathrm{E}-25$ & $96.96 \pm 8.02$ & $2.15 \pm 3.29$ & $0.928(0.908-0.948)$ \\
\hline KIRP & KLK1 & -94.2 & $2.70 \mathrm{E}-14$ & $357.84 \pm 7.72$ & $3.80 \pm 5.92$ & $0.943(0.915-0.971)$ \\
\hline KIRP & KLK6 & -41.6 & $7.81 \mathrm{E}-13$ & $157.05 \pm 6.67$ & $3.78 \pm 6.23$ & $0.902(0.867-0.937)$ \\
\hline KIRP & KLK7 & -48.0 & $8.28 \mathrm{E}-12$ & $86.20 \pm 8.12$ & $1.79 \pm 2.71$ & $0.906(0.871-0.941)$ \\
\hline THCA & KLK15 & -6.1 & $5.04 \mathrm{E}-34$ & $16.04 \pm 1.95$ & $2.61 \pm 3.41$ & $0.905(0.879-0.931)$ \\
\hline THCA & KLK2 & -13.2 & $2.91 \mathrm{E}-61$ & $124.18 \pm 1.77$ & $9.39 \pm 4.30$ & $0.943(0.923-0.963)$ \\
\hline THCA & KLK4 & -9.2 & $1.72 \mathrm{E}-45$ & $103.67 \pm 1.91$ & $11.22 \pm 4.75$ & $0.914(0.890-0.938)$ \\
\hline
\end{tabular}

\section{DISCUSSION}

In this study, the expression levels of 15 kallikrein genes were analyzed in 15 cancers using the TCGA gene expression dataset. Apart from changes in the expression, the effect of different KLKs on prognosis of cancers and their biomarker potential was also evaluated. Our study revealed that several KLKs have biomarker potential and can be used clinically in a diagnostic capacity in addition to kallikreins associated with patient survival in four cancer types. Our results support the existing literature that the expression of kallikreins is cancerspecific, as several kallikreins are upregulated in some cancer types and downregulated in other cancers [5]. The most novel findings from this study relate to the renal cell carcinoma subtypes. Our results indicate that renal clear cell and papillary carcinomas have nearly identical decreases in kallikrein expression profiles, whereas chromophobe renal cell carcinoma is a unique subtype as it had dramatic increases in some kallikreins (Figure 2). There is considerable morphology overlap between different subtypes of renal carcinomas [25]. Therefore, the unique association of various kallikreins with these subtypes will provide new biomarkers to differentiate them clinically.

\section{Renal clear cell carcinoma}

All 15 KLKs are known to be expressed in normal kidneys, both at the mRNA and protein level [26, 27]. Renal clear cell carcinoma is the most prevalent subtype of renal cell carcinoma [28]. Our analysis indicated that $K L K s 1,3,5,6,7,10$ and 15 were significantly decreased in renal clear cell carcinoma. The kallikrein-kinin system has been associated with inhibiting various kidney diseases by decreasing reactive oxygen species damage in the kidney; the downregulation of KLKs may decrease these protective effects [29-31]. In an earlier study using immunohistochemical analysis, $K L K 6$ and $K L K 7$ have been shown to have lower expression in high grade, in contrast to low grade renal cell carcinoma [32]. Other studies have also shown that expression of several KLKs including $K L K s$ 1, 3, 5, 6, 7, 10 and 15 is either decreased or not detected in renal cancer [27, 33, 34].

\section{Renal papillary cell carcinoma}

In previous studies, renal tubular epithelium has shown cytoplasmic immunohistochemical expression of several KLKs including KLK5, KLK6, KLK7, KLK10, KLK11, KLK13 and KLK14 [34, 35]. Earlier studies 
indicate decreased expression of $K L K S 1$ and 15 and increased expression of $K L K s \quad 6$ and 7 in renal papillary cell carcinoma [33, 35, 36]. Our analysis also found significant decreases in the expression of $K L K S 1,2,5,6,7$ and 15 . The similar profiles in renal clear cell and papillary carcinoma would give credence to the idea that these two cancers might have similar molecular mechanisms. KLKs 1, 6 and 7 can serve as novel biomarkers for renal papillary carcinoma, where absence of expression of these KLKs indicates tumor. In survival analysis, we confirmed one
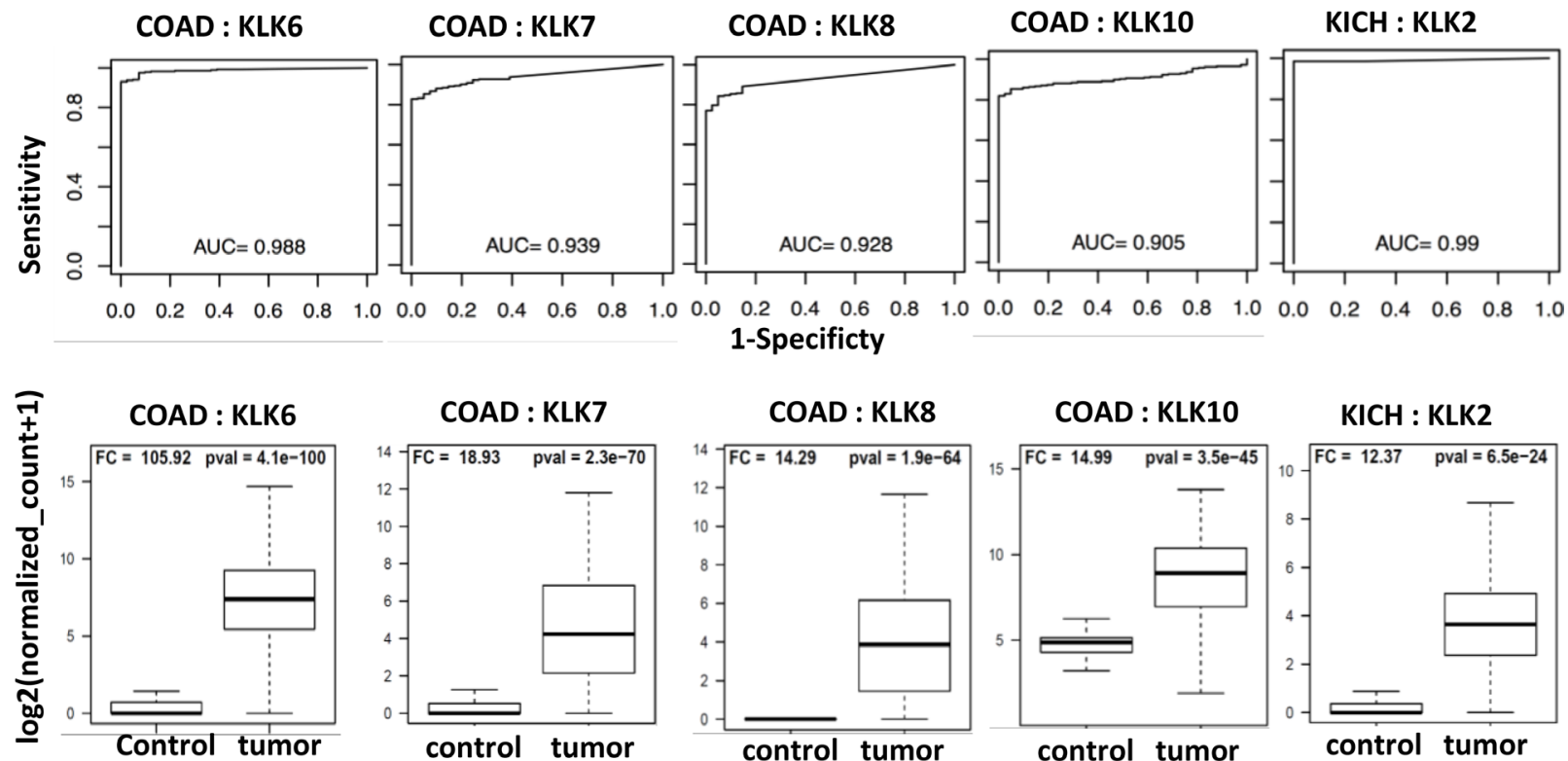

KICH : KLK2

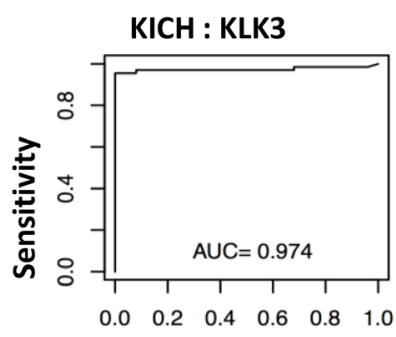

KICH : KLK4

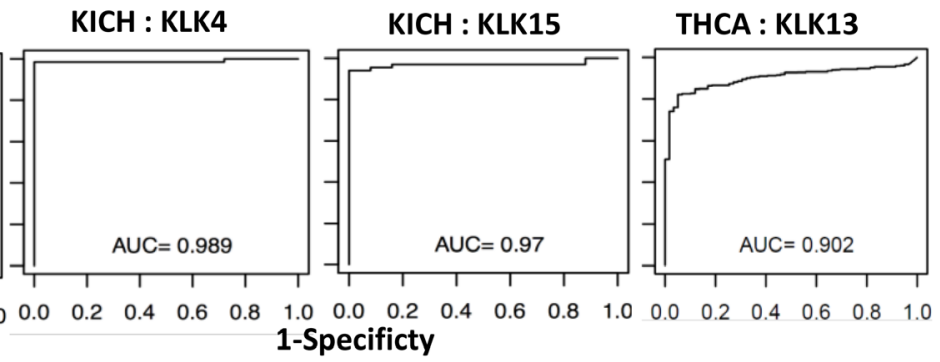

THCA : KLK13
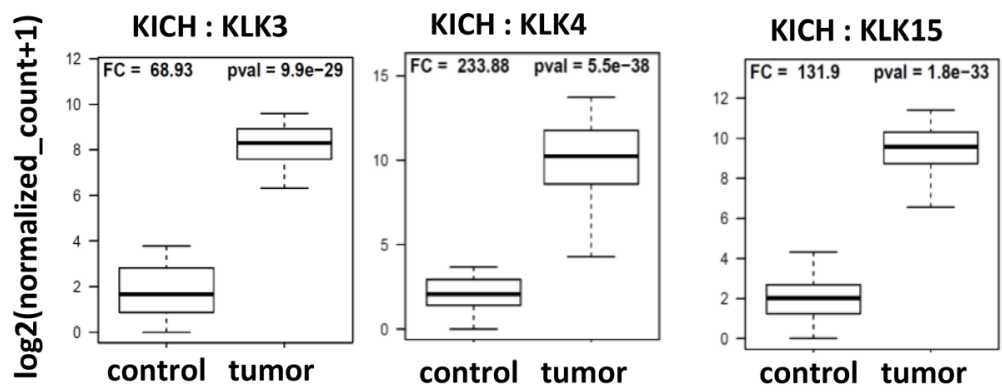

THCA : KLK13

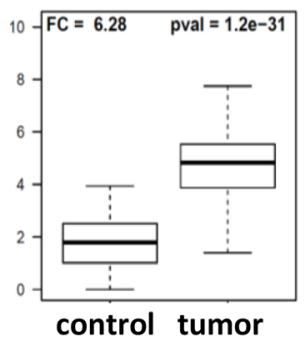

COAD: Colon adenocarcinoma

$\mathrm{KICH}$ : Chromophobe renal cell carcinoma

THCA: Thyroid carcinoma

Figure 3: Receiver operating curves (ROC) of kallikreins upregulated in cancers. The diagnostic power of individual KLK genes to differentiate cancer patients and respective controls was assessed using the area under the curve (AUC) of the receiver operating characteristic (ROC) curves. The ROC curves and AUC values of top performing KLKs (AUC > 0.90) are shown. The boxplots represent the distribution of expression in tumor and control samples. 
kallikrein (KLKO) that had previously been associated with poor survival [35] and identified one kallikrein (KLK7) that previously had not been implicated in prognosis of this cancer.

\section{Chromophobe renal cell carcinoma}

Previously published studies have shown decreased expression of $K L K s$ 1, 6 and 15 with a weak expression of $K L K 7$ with immunohistochemical analysis [32]. Our analysis differed and found that $K L K 1, K L K 2, K L K 3$, $K L K 4$ and $K L K 15$ are highly upregulated in chromophobe renal cell carcinoma. We hypothesize that the increase in these five kallikreins may cause increased expression of UPA and the destruction of the ECM, which has been shown to be active in renal carcinoma [37-39]. KLK5 and $K L K 6$ are decreased in all three types of the renal carcinomas. We identified four viable cancer biomarkers

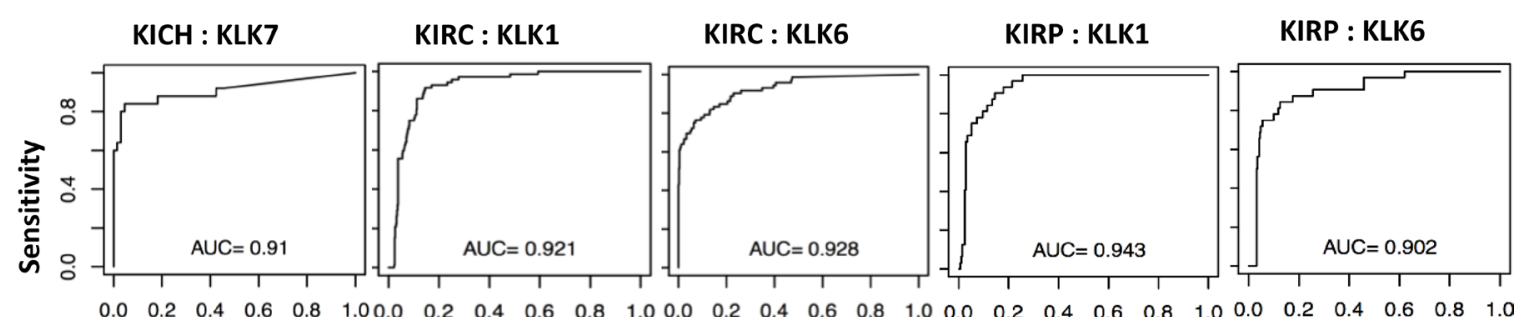

1-Specificty
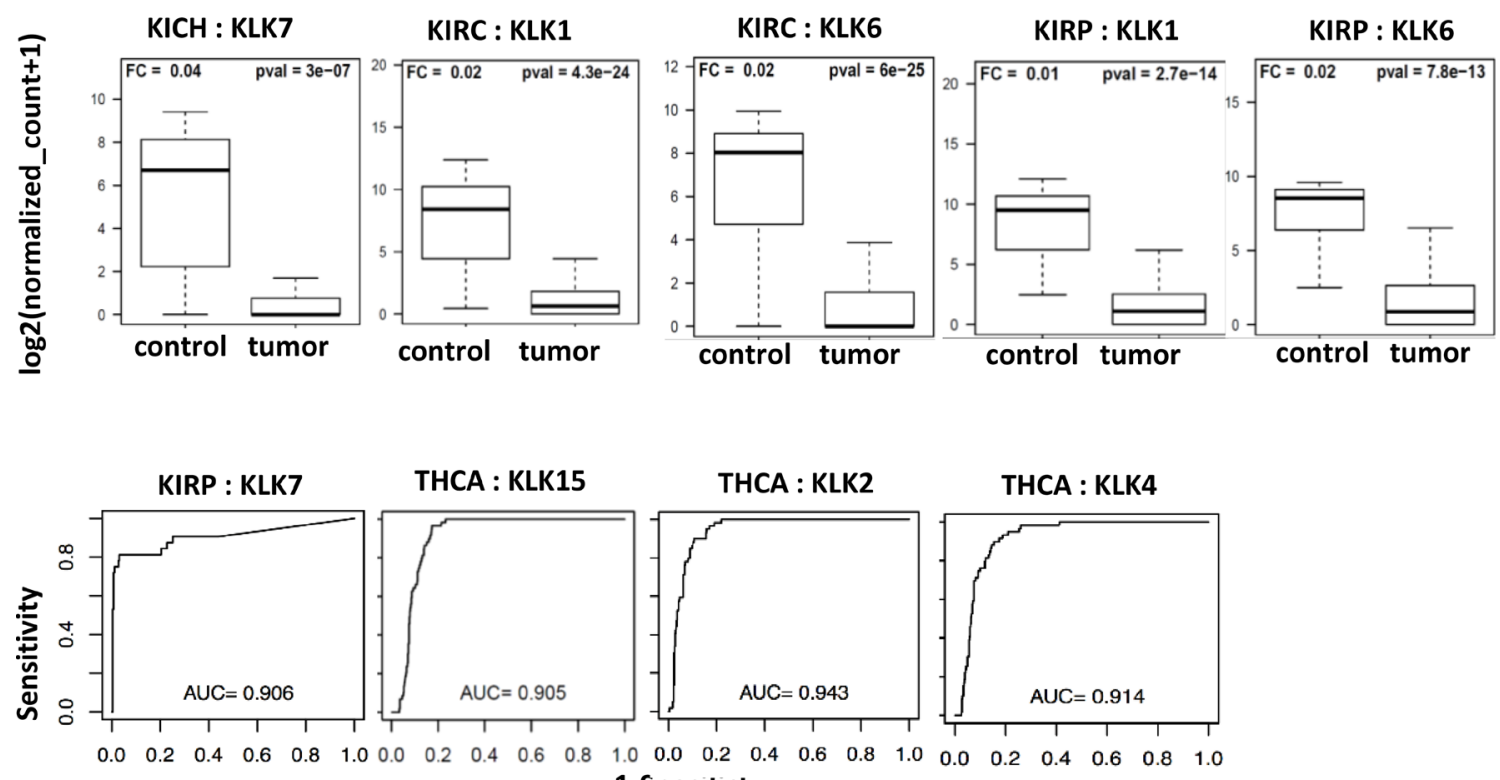

1-Speciticty

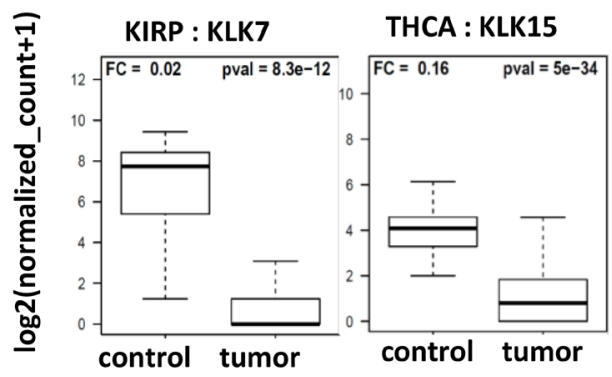

THCA : KLK2

THCA : KLK4

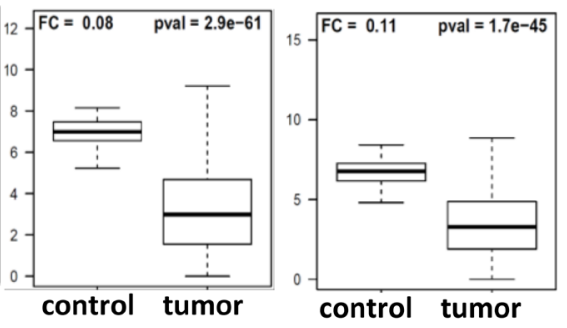

$\mathrm{KICH}$ : Chromophobe renal cell carcinoma KIRP: Renal papillary carcinoma

KIRC: Renal clear cell carcinoma

THCA: Thyroid carcinoma

Figure 4: Receiver operating curves (ROC) of kallikreins downregulated in cancers. The diagnostic power of individual KLK genes to differentiate cancer patients and respective controls was assessed using the area under the curve (AUC) of the receiver operating characteristic (ROC) curves. The ROC curves and AUC values of top performing KLKs (AUC > 0.90) are shown. Expression of these KLKs is negligible in tumor samples as compared to controls. The boxplots represent the distribution of expression in tumor and control samples. 
(KLK2, KLK3, KLK4 and KLK15) for chromophobe renal cell carcinoma with almost perfect sensitivity and specificity (AUC values: 0.97-0.99).

\section{Colon adenocarcinoma}

Significant increases in expression of $K L K S 6,7$, 8, 10, 11 and 12 and decreases in KLKs 1, 3, 13 and 15 were found in analysis of colon adenocarcinoma. Previous literature has shown increased expression of KLKs 6, 7, 10, 11 and 15 [40-46]. The nearly 19-fold increase in $K L K 7$ is consistent with Walker et al.'s findings of increased expression in $K L K 7$ leading to enhanced cell proliferation in the colon [47]. KLK7 expression is also increased in the thyroid; however, the majority of the tissues experienced a downregulation of $K L K 7$, indicating that the cell proliferative effects might be tissue-specific.
The increase in KLK12 may lead to increased angiogenesis in endothelial cells as described in a prior study [48]. Our analysis indicated that KLKs 6, 7, 8 and 10 are excellent diagnostic biomarkers for colon adenocarcinoma. Talieri et al., found that KLK5, KLK7 and KLK14 were significant factors for prognosis [49]; however, we did not find any kallikreins significantly associated with prognosis of colon adenocarcinoma.

\section{Thyroid carcinoma}

Thyroid hormones regulate kallikrein levels, and the dysfunction of thyroid hormones during thyroid carcinoma may lead to the dramatic changes in the kallikreins' expression $[19,50]$. Our analysis indicated significant increases in KLKs 5, 6, 7, 10, 11, 12 and 13 and decreases in KLKs 1, 2, 3, 4 and 15. Previous studies have obtained
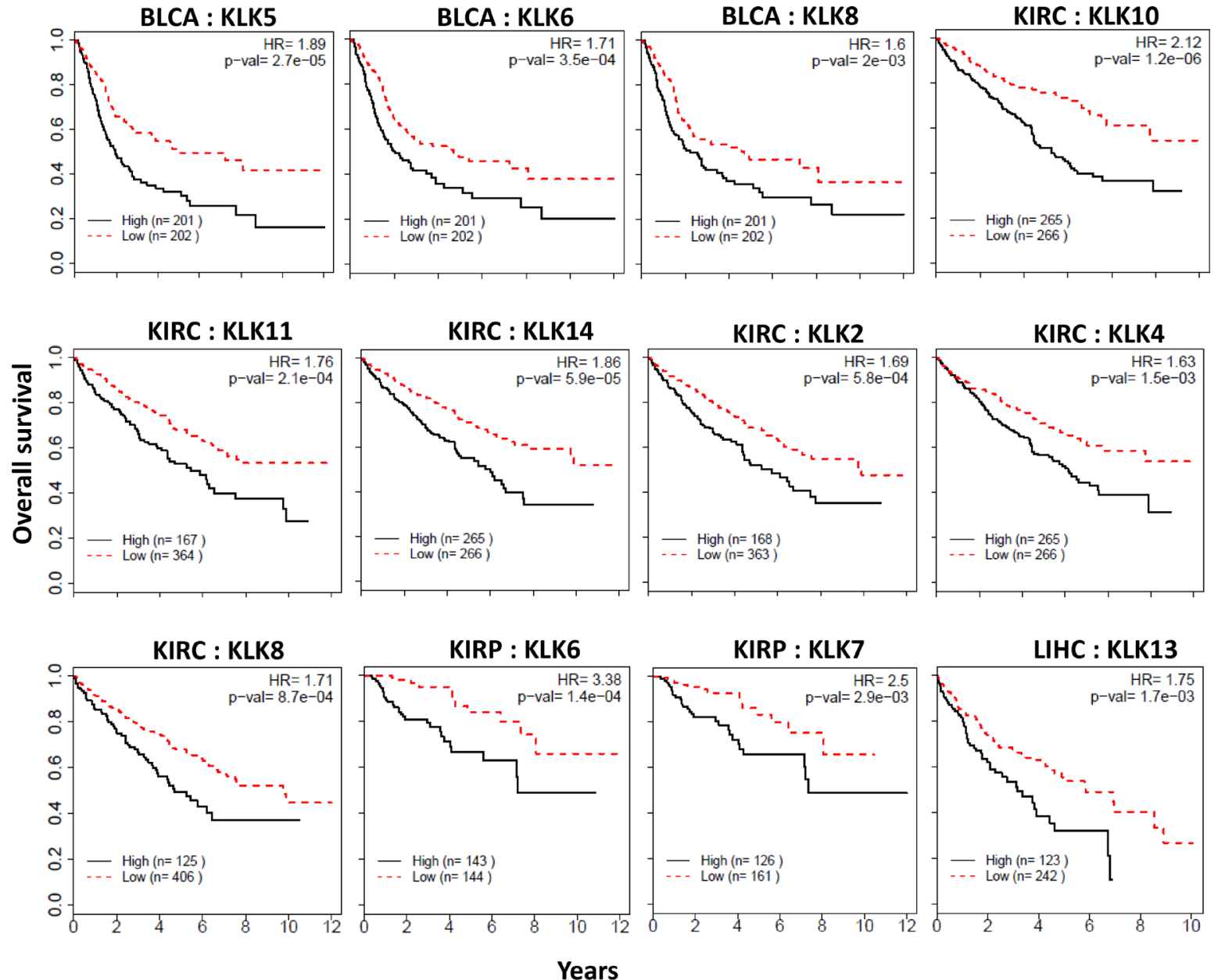

\section{BLCA: Urothelial Bladder Carcinoma KIRP: Renal papillary carcinoma}

\section{KIRC: Renal clear cell carcinoma \\ LIHC: Liver hepatocellular carcinoma}

Figure 5: Kallikreins associated with cancer prognosis. Kallikreins were independently assessed across the 15 cancers to determine if the expression of kallikrein is associated with overall survival. Kaplan-Meier survival analysis and log-rank test were used to compare differences in overall survival between groups classified using median expression as cut-off. Survival curves, hazard ratio (HR) and $p$-values are shown. 
similar results concerning the expression of KLKs 2, 3 and $7[51,52]$. Also, our ROC analysis indicates that $K L K 2$ and $K L K 4$ can be used as novel biomarkers for thyroid cancer, since previous studies have not reported any kallikreins as biomarkers for thyroid cancer.

\section{Lung adenocarcinoma}

Significant decreases in $K L K s$ 5, 7, 10 and 11, while significant increases in $K L K s$ 6, 8 and 12 were observed in differential expression analysis. Previous studies have also found increased expression of $K L K s$, 10 and 11 and decreased expression of $6,8,7$, and 12 in lung adenocarcinoma [53-56]. KLK12 is known to stimulate angiogenesis via a platelet-derived growth factor-B $(P D G F B)$ dependent paracrine pathway [48]. Increased $K L K 8$ has been associated with a favorable clinical outcome in lung adenocarcinoma by suppressing tumor invasiveness through inhibition of integrin signaling and cell adhesion [57]; however we could not confirm this finding in our study.

\section{Lung squamous cell carcinoma}

Differential expression analysis indicated increased expression of KLKs 2, 6, 8, 9, 12 and 13 and decreased expression of $K L K 11$. However, KLK11 is known to be overexpressed lung squamous cell carcinoma [58]. Previous studies have found similar increased expression patterns for $K L K 6$ and $K L K 8[55,59]$. The increased expression of KLKs 2, 9, 12 and 13 are novel findings in our study.

\section{Hepatocellular carcinoma}

Hepatocellular carcinoma has a significant decrease in the expression of KLK10 and KLK11. Decreased expression of $K L K 10$ is consistent with earlier findings [44] while the decreased expression of KLK11 in hepatocellular carcinoma is previously unknown.

\section{Head-neck squamous cell carcinoma}

KLK6 expression was decreased in head-neck squamous cell carcinoma, in contrast to earlier findings [60]. We also found significant decrease in the expression of $K L K s 3,7,11,12$ and 13 that were previously not known. A prior study found increased expression of $K L K 10$ in Group 1 tumor subtype; however, our analysis did not find $K L K 10$ expression to be significantly different [61].

\section{Breast invasive carcinoma}

KLKs 2, 3, 5, 6, 7, 10, 11, 13 and 14 were found to have significantly decreased expression in breast invasive carcinoma. These findings are mostly consistent with previously published studies $[6,9,22,62-68]$. Decreased $K L K 7$ in breast cancer is a novel finding. $K L K 4$ was the only kallikrein overexpressed and was consistent with earlier findings of increased expression in malignant tumors [69].

\section{Uterine corpus endometrial carcinoma}

The expression of three kallikreins ( $K L K s 1,2$ and 4) was found to be decreased in uterine endometrial cancer. Dorn et al. found similar expression changes for KLK1 but also found increases in the expression of $K L K s 6,8$ and $10[36]$.

\section{Prostate adenocarcinoma}

Differential expression analysis indicated dramatic changes in the expression of $K L K 2,3,4,12,14$ and 15. Published literature is consistent with $K L K 3,4,14$ and 15 expression changes, but was the opposite for $K L K 2$ in malignant tumors $[6,70]$. Increased expression of $K L K 12$ was not reported earlier and serves as a new discovery.

\section{Urothelial bladder carcinoma}

Our analyses found significant increases in the expression of $K L K 2$ and $K L K 4$. We also found that three kallikreins (KLKs 5, 6 and 8) were significantly associated with overall survival in urothelial bladder carcinoma. Previous studies found increased expression in KLKs 5 , 6,8 and $9[6,36]$. Also, down-regulation of $K L K 13$ was associated with an unfavorable prognosis [71]; however we did not find KLK13 expression to have a significant effect on survival.

\section{Stomach adenocarcinoma}

In stomach adenocarcinoma, the only significant change in expression was found in KLK6 (11-fold upregulated). Other studies for gastric cancer have found increased expression of KLKs 6 and 12 and decreased expression of $K L K s 10,11$ and 13 [6, 44, 72].

\section{Esophageal carcinoma}

In our analysis KLK4 expression was increased 3 -fold in esophageal carcinoma. Two earlier studies have found increased expression of $K L K 6$ [44, 66]. In our study $K L K 6$ was increased in esophageal carcinoma, but could not achieve statistical significance.

\section{METHODS}

\section{TCGA datasets}

The TCGA gene expression RNAseq data (IlluminaHiSeq: $\quad \log 2$-normalized_count +1 ) was downloaded from Xena browser (https://xenabrowser. net/datapages/). We selected 15 cancer types for analyses 
having at least 10 adjacent normal samples: Renal clear cell carcinoma (KIRC), Renal papillary carcinoma (KIRP), Chromophobe renal cell carcinoma (KICH), Colon adenocarcinoma (COAD), Thyroid carcinoma (THCA), Lung adenocarcinoma (LUAD), Lung squamous cell carcinoma (LUSC), Hepatocellular carcinoma (LIHC), Head and Neck squamous cell carcinoma (HNSC), Breast invasive carcinoma (BRCA), Uterine Corpus Endometrial Carcinoma (UCEC), Prostate adenocarcinoma (PRAD), Urothelial Bladder Carcinoma (BLCA), Stomach adenocarcinoma (STAD) and Esophageal carcinoma (ESCA). Statistical analyses were performed to compare and contrast the expression levels of 15 kallikrein genes in these 15 cancer types.

\section{Statistical analyses}

All statistical analyses were performed using the $\mathrm{R}$ language and environment for statistical computing $(\mathrm{R}$ version 3.2.2; R Foundation for Statistical Computing; www.r-project.org). The potential differences in the gene expression between cancer patients and adjacent normal were examined. To express the amount and significance of change, Fold change (FC: Cancer $v s$ Adjacent Normal) and $p$-values (pval) were calculated. The dot plots were created to visualize the distribution of gene expression in cancer patients and adjacent normal (expression levels in each subject represented by a dot). The diagnostic power of individual KLK genes to differentiate cancer patients and respective controls was assessed using the area under the curve (AUC) of the receiver operating characteristic (ROC) curves. We used Cox proportional hazards models to evaluate the impact of gene expression levels on overall survival. Overall survival data (diagnosis to date of death) were downloaded from the TCGA patient phenotype files. Patients who are alive with no evidence of disease were censored at the date of last follow-up visit. Kaplan-Meier survival analysis and log-rank test were used to compare differences in overall survival between groups classified using different cut-offs of expression level.

\section{CONCLUSIONS}

Previous studies have shown that kallikreins can serve as biomarkers to help diagnose individuals with cancer and are also associated with prognosis and mortality. However, the expression and function of kallikreins is known to be tissue-specific. Our analysis explored the expression of every member of the kallikrein family in 15 cancer types, yielding a comprehensive overview of KLK expression in these cancers. In this study, differential expression analysis indicated that every cancer had at least one kallikrein that had a significant change in expression, with some cancers having up to 12 kallikreins significantly altered. Analysis of kallikrein expression performed on the subtypes of renal cell carcinoma was essentially novel as the subtypes had been explored minimally in previous studies. Renal clear cell and papillary carcinomas appear to have similar kallikrein expression, while chromophobe renal cell carcinoma displayed dramatic overexpression. Our analysis indicates multiple kallikreins can serve as biomarkers for diagnosis for all three renal subtypes with high sensitivity and specificity. Novel diagnostic biomarkers for colon adenocarcinoma and thyroid carcinoma were also identified. In addition to the renal carcinomas, several kallikreins in urothelial bladder carcinoma and headneck squamous cell carcinoma can serve as prognostic indicators. Further studies need to be conducted exploring the utilization of kallikreins as a diagnostic or prognostic tool. Also, studies are needed to elucidate the precise mechanisms of kallikreins in various cancers which can help in personalized medicine and lead to improved outcomes in patients with more specific drug regimes.

\section{CONFLICTS OF INTEREST}

None.

\section{REFERENCES}

1. Diamandis EP, Yousef GM. Human tissue kallikreins: a family of new cancer biomarkers. Clin Chem. 2002; 48:1198-205.

2. Yousef GM, Scorilas A, Katsaros D, Fracchioli S, Iskander L, Borgono C, Rigault de la Longrais IA, Puopolo M, Massobrio M, Diamandis EP. Prognostic value of the human kallikrein gene 15 expression in ovarian cancer. J Clin Oncol. 2003; 21:3119-26. https://doi.org/10.1200/ JCO.2003.09.111.

3. Fortier AH, Nelson BJ, Grella DK, Holaday JW. Antiangiogenic activity of prostate-specific antigen. J Natl Cancer Inst. 1999; 91:1635-40.

4. Prassas I, Eissa A, Poda G, Diamandis EP. Unleashing the therapeutic potential of human kallikrein-related serine proteases. Nat Rev Drug Discov. 2015; 14:183-202. https:// doi.org/10.1038/nrd4534.

5. Borgono CA, Diamandis EP. The emerging roles of human tissue kallikreins in cancer. Nat Rev Cancer. 2004; 4:87690. https://doi.org/10.1038/nrc1474.

6. Paliouras M, Borgono C, Diamandis EP. Human tissue kallikreins: the cancer biomarker family. Cancer Lett. 2007; 249:61-79. https://doi.org/10.1016/j.canlet.2006.12.018.

7. Cleutjens $\mathrm{KB}$, van Eekelen $\mathrm{CC}$, van der Korput HA, Brinkmann AO, Trapman J. Two androgen response regions cooperate in steroid hormone regulated activity of the prostate-specific antigen promoter. J Biol Chem. 1996; 271:6379-88.

8. Smith MS, Lechago J, Wines DR, MacDonald RJ, Hammer RE. Tissue-specific expression of kallikrein family 
transgenes in mice and rats. DNA Cell Biol. 1992; 11:34558. https://doi.org/10.1089/dna.1992.11.345.

9. Borgono CA, Grass L, Soosaipillai A, Yousef GM, Petraki CD, Howarth DH, Fracchioli S, Katsaros D, Diamandis EP. Human kallikrein 14: a new potential biomarker for ovarian and breast cancer. Cancer Res. 2003; 63:9032-41.

10. Fagerberg L, Hallstrom BM, Oksvold P, Kampf C, Djureinovic D, Odeberg J, Habuka M, Tahmasebpoor S, Danielsson A, Edlund K, Asplund A, Sjostedt E, Lundberg $\mathrm{E}$, et al. Analysis of the human tissue-specific expression by genome-wide integration of transcriptomics and antibodybased proteomics. Mol Cell Proteomics. 2014; 13:397-406. https://doi.org/10.1074/mcp.M113.035600.

11. Frenette G, Tremblay RR, Lazure C, Dube JY. Prostatic kallikrein $\mathrm{hK} 2$, but not prostate-specific antigen (hK3), activates single-chain urokinase-type plasminogen activator. Int J Cancer. 1997; 71:897-9.

12. Killian CS, Corral DA, Kawinski E, Constantine RI. Mitogenic response of osteoblast cells to prostate-specific antigen suggests an activation of latent TGF-beta and a proteolytic modulation of cell adhesion receptors. Biochem Biophys Res Commun. 1993; 192:940-7. https://doi. org/10.1006/bbrc.1993.1506.

13. Webber MM, Waghray A, Bello D. Prostate-specific antigen, a serine protease, facilitates human prostate cancer cell invasion. Clin Cancer Res. 1995; 1:1089-94.

14. Tschesche H, Michaelis J, Kohnert U, Fedrowitz J, Oberhoff R. Tissue kallikrein effectively activates latent matrix degrading metalloenzymes. Adv Exp Med Biol. 1989; 247A: 545-8.

15. Desrivieres S, Lu H, Peyri N, Soria C, Legrand Y, Menashi $\mathrm{S}$. Activation of the $92 \mathrm{kDa}$ type IV collagenase by tissue kallikrein. J Cell Physiol. 1993; 157:587-93. https://doi. org/10.1002/jcp.1041570319.

16. Rehault S, Monget P, Mazerbourg S, Tremblay R, Gutman $\mathrm{N}$, Gauthier F, Moreau T. Insulin-like growth factor binding proteins (IGFBPs) as potential physiological substrates for human kallikreins hK2 and hK3. Eur J Biochem. 2001; 268:2960-8.

17. Takayama TK, McMullen BA, Nelson PS, Matsumura M, Fujikawa K. Characterization of hK4 (prostase), a prostatespecific serine protease: activation of the precursor of prostate specific antigen (pro-PSA) and single-chain urokinase-type plasminogen activator and degradation of prostatic acid phosphatase. Biochemistry. 2001; 40:15341-8.

18. Magklara A, Mellati AA, Wasney GA, Little SP, Sotiropoulou G, Becker GW, Diamandis EP. Characterization of the enzymatic activity of human kallikrein 6: Autoactivation, substrate specificity, and regulation by inhibitors. Biochem Biophys Res Commun. 2003; 307:948-55.

19. Sotiropoulou G, Rogakos V, Tsetsenis T, Pampalakis G, Zafiropoulos N, Simillides G, Yiotakis A, Diamandis
EP. Emerging interest in the kallikrein gene family for understanding and diagnosing cancer. Oncol Res. 2003; 13:381-91.

20. Tamir A, Jag U, Sarojini S, Schindewolf C, Tanaka T, Gharbaran R, Patel H, Sood A, Hu W, Patwa R, Blake P, Chirina $\mathrm{P}$, Oh Jeong $\mathrm{J}$, et al. Kallikrein family proteases KLK6 and KLK7 are potential early detection and diagnostic biomarkers for serous and papillary serous ovarian cancer subtypes. J Ovarian Res. 2014; 7:109. https://doi.org/10.1186/s13048-014-0109-z.

21. Yousef GM, Diamandis EP. Expanded human tissue kallikrein family - a novel panel of cancer biomarkers. Tumour Biol. 2002; 23:185-92. https://doi.org/64027.

22. Yousef GM, Scorilas A, Nakamura T, Ellatif MA, Ponzone R, Biglia N, Maggiorotto F, Roagna R, Sismondi P, Diamandis EP. The prognostic value of the human kallikrein gene 9 (KLK9) in breast cancer. Breast Cancer Res Treat. 2003; 78:149-58.

23. Kolin DL, Sy K, Rotondo F, Bassily MN, Kovacs K, Brezden-Masley C, Streutker CJ, Yousef GM. Prognostic significance of human tissue kallikrein-related peptidases 6 and 10 in gastric cancer. Biol Chem. 2014; 395:1087-93. https://doi.org/10.1515/hsz-2014-0143.

24. Kolin DL, Sy K, Rotondo F, Bassily MN, Kovacs K, Brezden-Masley C, Streutker CJ, Yousef GM. Prognostic significance of human tissue kallikrein-related peptidases 11 and 15 in gastric cancer. Tumour Biol. 2016; 37:437-46. https://doi.org/10.1007/s13277-015-3802-7.

25. Sircar K, Rao P, Jonasch E, Monzon FA, Tamboli P. Contemporary approach to diagnosis and classification of renal cell carcinoma with mixed histologic features. Chin J Cancer. 2013; 32:303-11. https://doi.org/10.5732/ cjc.012.10136.

26. Shaw JL, Diamandis EP. Distribution of 15 human kallikreins in tissues and biological fluids. Clin Chem. 2007; 53:1423-32. https://doi.org/10.1373/clinchem.2007.088104.

27. Petraki CD, Papanastasiou PA, Karavana VN, Diamandis EP. Cellular distribution of human tissue kallikreins: immunohistochemical localization. Biol Chem. 2006; 387:653-63. https://doi.org/10.1515/BC.2006.084.

28. Delahunt B, Cheville JC, Martignoni G, Humphrey PA, Magi-Galluzzi C, McKenney J, Egevad L, Algaba F, Moch H, Grignon DJ, Montironi R, Srigley JR, Members of the IRTP. The International Society of Urological Pathology (ISUP) grading system for renal cell carcinoma and other prognostic parameters. Am J Surg Pathol. 2013; 37:1490504. https://doi.org/10.1097/PAS.0b013e318299f0fb.

29. Kakoki M, Smithies O. The kallikrein-kinin system in health and in diseases of the kidney. Kidney Int. 2009; 75:1019-30. https://doi.org/10.1038/ki.2008.647.

30. Jozwiak L, Drop A, Buraczynska K, Ksiazek P, Mierzicki P, Buraczynska M. Association of the human bradykinin B2 receptor gene with chronic renal failure. Mol Diagn. 2004; $8: 157-61$. 
31. Asakimori Y, Yorioka N, Yamamoto I, Okumoto S, Doi S, Hirai T, Taniguchi Y. Endothelial nitric oxide synthase intron 4 polymorphism influences the progression of renal disease. Nephron. 2001; 89:219-23. https://doi. org/10.1159/000046071.

32. Gabril M, White NM, Moussa M, Chow TF, Metias SM, Fatoohi E, Yousef GM. Immunohistochemical analysis of kallikrein-related peptidases in the normal kidney and renal tumors: potential clinical implications. Biol Chem. 2010; 391:403-9. https://doi.org/10.1515/BC.2010.025.

33. White NM, Bui A, Mejia-Guerrero S, Chao J, Soosaipillai A, Youssef Y, Mankaruos M, Honey RJ, Stewart R, Pace KT, Sugar L, Diamandis EP, Dore J, et al. Dysregulation of kallikrein-related peptidases in renal cell carcinoma: potential targets of miRNAs. Biol Chem. 2010; 391:411-23. https://doi.org/10.1515/BC.2010.041.

34. Dumas F, Gala JL, Berteau P, Brasseur F, Eschwege P, Paradis V, Lacour B, Philippe M, Loric S. Molecular expression of PSMA mRNA and protein in primary renal tumors. Int J Cancer. 1999; 80:799-803.

35. Petraki CD, Gregorakis AK, Vaslamatzis MM, Papanastasiou PA, Yousef GM, Levesque MA, Diamandis EP. Prognostic implications of the immunohistochemical expression of human kallikreins 5, 6, 10 and 11 in renal cell carcinoma. Tumour Biol. 2006; 27:1-7. https://doi. org/10.1159/000090150.

36. Dorn J, Bayani J, Yousef GM, Yang F, Magdolen V, Kiechle M, Diamandis EP, Schmitt M. Clinical utility of kallikreinrelated peptidases (KLK) in urogenital malignancies. Thromb Haemost. 2013; 110:408-22. https://doi. org/10.1160/TH13-03-0206.

37. Fuessel S, Erdmann K, Taubert H, Lohse-Fischer A, Zastrow S, Meinhardt M, Bluemke K, Hofbauer L, Fornara P, Wullich B, Baretton G, Magdolen V, Wirth MP, et al. Prognostic impact of urokinase-type plasminogen activator system components in clear cell renal cell carcinoma patients without distant metastasis. BMC Cancer. 2014; 14: 974. https://doi.org/10.1186/1471-2407-14-974.

38. Hofmann R, Lehmer A, Buresch M, Hartung R, Ulm K. Clinical relevance of urokinase plasminogen activator, its receptor, and its inhibitor in patients with renal cell carcinoma. Cancer. 1996; 78:487-92. https://doi. org/10.1002/(SICI)1097-0142(19960801)78:3<487::AIDCNCR16>3.0.CO;2-V.

39. Hofmann R, Lehmer A, Hartung R, Robrecht C, Buresch $\mathrm{M}$, Grothe F. Prognostic value of urokinase plasminogen activator and plasminogen activator inhibitor-1 in renal cell cancer. J Urol. 1996; 155:858-62.

40. Sells E, Pandey R, Chen H, Skovan BA, Cui H, Ignatenko NA. Specific microRNA-mRNA Regulatory Network of Colon Cancer Invasion Mediated by Tissue KallikreinRelated Peptidase 6. Neoplasia. 2017; 19:396-411. https:// doi.org/10.1016/j.neo.2017.02.003.

41. Alexopoulou DK, Papadopoulos IN, Scorilas A. Clinical significance of kallikrein-related peptidase
(KLK10) mRNA expression in colorectal cancer. Clin Biochem. 2013; 46:1453-61. https://doi.org/10.1016/j. clinbiochem.2013.03.002.

42. Christodoulou S, Alexopoulou DK, Kontos CK, Scorilas A, Papadopoulos IN. Kallikrein-related peptidase-6 (KLK6) mRNA expression is an independent prognostic tissue biomarker of poor disease-free and overall survival in colorectal adenocarcinoma. Tumour Biol. 2014; 35:467385. https://doi.org/10.1007/s13277-014-1612-y.

43. Feng B, Xu WB, Zheng MH, Ma JJ, Cai Q, Zhang Y, Ji J, Lu AG, Qu Y, Li JW, Wang ML, Hu WG, Liu BY, et al. Clinical significance of human kallikrein 10 gene expression in colorectal cancer and gastric cancer. J Gastroenterol Hepatol. 2006; 21:1596-603. https://doi. org/10.1111/j.1440-1746.2006.04228.x.

44. Kontos CK, Mavridis K, Talieri M, Scorilas A. Kallikreinrelated peptidases (KLKs) in gastrointestinal cancer: mechanistic and clinical aspects. Thromb Haemost. 2013; 110:450-7. https://doi.org/10.1160/TH12-11-0791.

45. Alexopoulou DK, Kontos CK, Christodoulou S, Papadopoulos IN, Scorilas A. KLK11 mRNA expression predicts poor disease-free and overall survival in colorectal adenocarcinoma patients. Biomark Med. 2014; 8:671-85. https://doi.org/10.2217/bmm.13.151.

46. Yousef GM, Scorilas A, Jung K, Ashworth LK, Diamandis EP. Molecular cloning of the human kallikrein 15 gene (KLK15). Up-regulation in prostate cancer. J Biol Chem. 2001; 276:53-61. https://doi.org/10.1074/jbc.M005432200.

47. Walker F, Nicole P, Jallane A, Soosaipillai A, Mosbach V, Oikonomopoulou K, Diamandis EP, Magdolen V, Darmoul D. Kallikrein-related peptidase 7 (KLK7) is a proliferative factor that is aberrantly expressed in human colon cancer. Biol Chem. 2014; 395:1075-86. https://doi.org/10.1515/ hsz-2014-0142.

48. Kryza T, Achard C, Parent C, Marchand-Adam S, GuillonMunos A, Iochmann S, Korkmaz B, Respaud R, Courty Y, Heuze-Vourc'h N. Angiogenesis stimulated by human kallikrein-related peptidase 12 acting via a platelet-derived growth factor B-dependent paracrine pathway. FASEB J. 2014; 28:740-51. https://doi.org/10.1096/fj.13-237503.

49. Talieri M, Li L, Zheng Y, Alexopoulou DK, Soosaipillai A, Scorilas A, Xynopoulos D, Diamandis EP. The use of kallikrein-related peptidases as adjuvant prognostic markers in colorectal cancer. Br J Cancer. 2009; 100:1659-65. https://doi.org/10.1038/sj.bjc.6605033.

50. Sotiropoulou G, Pampalakis G. Kallikrein-related peptidases: bridges between immune functions and extracellular matrix degradation. Biol Chem. 2010; 391:321-31. https://doi.org/10.1515/BC.2010.036.

51. Kim HS, Kim DH, Kim JY, Jeoung NH, Lee IK, Bong JG, Jung ED. Microarray analysis of papillary thyroid cancers in Korean. Korean J Intern Med. 2010; 25:399-407. https:// doi.org/10.3904/kjim.2010.25.4.399.

52. Prasad NB, Somervell H, Tufano RP, Dackiw AP, Marohn MR, Califano JA, Wang Y, Westra WH, Clark DP, Umbricht 
CB, Libutti SK, Zeiger MA. Identification of genes differentially expressed in benign versus malignant thyroid tumors. Clin Cancer Res. 2008; 14:3327-37. https://doi. org/10.1158/1078-0432.CCR-07-4495.

53. Planque C, Li L, Zheng Y, Soosaipillai A, Reckamp K, Chia D, Diamandis EP, Goodglick L. A multiparametric serum kallikrein panel for diagnosis of non-small cell lung carcinoma. Clin Cancer Res. 2008; 14:1355-62. https://doi. org/10.1158/1078-0432.CCR-07-4117.

54. Sasaki H, Kawano O, Endo K, Suzuki E, Haneda H, Yukiue H, Kobayashi Y, Yano M, Fujii Y. Decreased kallikrein 11 messenger RNA expression in lung cancer. Clin Lung Cancer. 2006; 8:45-8. https://doi.org/10.3816/ CLC.2006.n.032.

55. Singh J, Naran A, Misso NL, Rigby PJ, Thompson PJ, Bhoola KD. Expression of kallikrein-related peptidases $(\mathrm{KRP} / \mathrm{hK} 5,7,6,8)$ in subtypes of human lung carcinoma. Int Immunopharmacol. 2008; 8:300-6. https://doi. org/10.1016/j.intimp.2007.08.015.

56. Planque C, de Monte M, Guyetant S, Rollin J, Desmazes C, Panel V, Lemarie E, Courty Y. KLK5 and KLK7, two members of the human tissue kallikrein family, are differentially expressed in lung cancer. Biochem Biophys Res Commun. 2005; 329:1260-6. https://doi.org/10.1016/j. bbrc.2005.02.100.

57. Sher YP, Chou CC, Chou RH, Wu HM, Wayne Chang WS, Chen CH, Yang PC, Wu CW, Yu CL, Peck K. Human kallikrein 8 protease confers a favorable clinical outcome in non-small cell lung cancer by suppressing tumor cell invasiveness. Cancer Res. 2006; 66:11763-70. https://doi. org/10.1158/0008-5472.CAN-06-3165.

58. Planque C, Ainciburu M, Heuze-Vourc'h N, Regina S, de Monte M, Courty Y. Expression of the human kallikrein genes 10 (KLK10) and 11 (KLK11) in cancerous and non-cancerous lung tissues. Biol Chem. 2006; 387:783-8. https://doi.org/10.1515/BC.2006.098.

59. Nathalie HV, Chris P, Serge G, Catherine C, Benjamin B, Claire B, Christelle P, Briollais L, Pascale R, Marie-Lise J, Yves C. High kallikrein-related peptidase 6 in non-small cell lung cancer cells: an indicator of tumour proliferation and poor prognosis. J Cell Mol Med. 2009; 13:4014-22. https://doi.org/10.1111/j.1582-4934.2009.00763.x.

60. Schrader CH, Kolb M, Zaoui K, Flechtenmacher C, Grabe N, Weber KJ, Hielscher T, Plinkert PK, Hess J. Kallikreinrelated peptidase 6 regulates epithelial-to-mesenchymal transition and serves as prognostic biomarker for head and neck squamous cell carcinoma patients. Mol Cancer. 2015; 14:107. https://doi.org/10.1186/s12943-015-0381-6.

61. Chung CH, Parker JS, Karaca G, Wu J, Funkhouser WK, Moore D, Butterfoss D, Xiang D, Zanation A, Yin X, Shockley WW, Weissler MC, Dressler LG, et al. Molecular classification of head and neck squamous cell carcinomas using patterns of gene expression. Cancer Cell. 2004; 5:489-500.
62. Howarth DJ, Aronson IB, Diamandis EP. Immunohistochemical localization of prostate-specific antigen in benign and malignant breast tissues. Br J Cancer. 1997; 75:1646-51.

63. Yu H, Diamandis EP, Levesque M, Giai M, Roagna R, Ponzone R, Sismondi P, Monne M, Croce CM. Prostate specific antigen in breast cancer, benign breast disease and normal breast tissue. Breast Cancer Res Treat. 1996; 40:171-8.

64. Yousef GM, Polymeris ME, Grass L, Soosaipillai A, Chan PC, Scorilas A, Borgono C, Harbeck N, Schmalfeldt B, Dorn J, Schmitt M, Diamandis EP. Human kallikrein 5: a potential novel serum biomarker for breast and ovarian cancer. Cancer Res. 2003; 63:3958-65.

65. Yousef GM, Yacoub GM, Polymeris ME, Popalis C, Soosaipillai A, Diamandis EP. Kallikrein gene downregulation in breast cancer. $\mathrm{Br} \mathrm{J}$ Cancer. 2004; 90:167-72. https://doi.org/10.1038/sj.bjc.6601451.

66. Yousef GM, Borgono CA, White NM, Robb JD, Michael IP, Oikonomopoulou K, Khan S, Diamandis EP. In silico analysis of the human kallikrein gene 6. Tumour Biol. 2004; 25:282-9. https://doi.org/10.1159/000081393.

67. Yousef GM, White NM, Michael IP, Cho JC, Robb JD, Kurlender L, Khan S, Diamandis EP. Identification of new splice variants and differential expression of the human kallikrein 10 gene, a candidate cancer biomarker. Tumour Biol. 2005; 26:227-35. https://doi.org/10.1159/000087377.

68. Yousef GM, Magklara A, Diamandis EP. KLK12 is a novel serine protease and a new member of the human kallikrein gene family-differential expression in breast cancer. Genomics. 2000; 69:331-41. https://doi.org/10.1006/ geno.2000.6346.

69. Papachristopoulou G, Avgeris M, Scorilas A. Expression analysis and study of KLK4 in benign and malignant breast tumours. Thromb Haemost. 2009; 101:381-7.

70. Gurova KV, Roklin OW, Krivokrysenko VI, Chumakov PM, Cohen MB, Feinstein E, Gudkov AV. Expression of prostate specific antigen (PSA) is negatively regulated by p53. Oncogene. 2002; 21:153-7. https://doi.org/10.1038/ sj.onc. 1205001.

71. Tokas T, Avgeris M, Alamanis C, Scorilas A, Stravodimos KG, Constantinides CA. Downregulated KLK13 expression in bladder cancer highlights tumor aggressiveness and unfavorable patients' prognosis. J Cancer Res Clin Oncol. 2017; 143:521-32. https://doi.org/10.1007/ s00432-016-2301-6.

72. Liu X, Xiong H, Li J, He Y, Yuan X. Correlation of hK6 expression with tumor recurrence and prognosis in advanced gastric cancer. Diagn Pathol. 2013; 8:62. https:// doi.org/10.1186/1746-1596-8-62. 